\title{
Clinico-radiological and functional outcomes of bicolumnar plating in Schatzker type 5 and type 6 fractures of proximal tibia in tertiary care hospital in North India: a series of 26 patients
}

\author{
Pankaj Vir Singh*, Gagandeep Singh, Manmeet Singh, Abdul Ghani, \\ Amarjeet Singh, Zubair A. Lone
}

Department of Orthopaedics, Government Medical College, Jammu, Jammu and Kashmir, India

Received: 12 April 2021

Revised: 17 April 2021

Accepted: 27 April 2021

*Correspondence:

Dr. Pankaj Vir Singh,

E-mail: pankajcoolpal@gmail.com

Copyright: () the author(s), publisher and licensee Medip Academy. This is an open-access article distributed under the terms of the Creative Commons Attribution Non-Commercial License, which permits unrestricted non-commercial use, distribution, and reproduction in any medium, provided the original work is properly cited.

\begin{abstract}
Background: Ideal mode of treatment is always debatable for Schatzker type 5 and type 6 fractures in proximal tibia. The aim of the study was management in tibial plateau fracture are to obtain anatomic reduction of the articular surface, restoration of axial alignment, and achieve stable fixation which can be done by open reduction and internal fixation (ORIF) using bicolumnar plating.

Methods: 26 patients with Schatzker type 5 and type 6 fractures were managed by bicolumnar plating. They were followed up to six months in terms of radiological union, functional outcomes and complications. Functional outcome at the end of follow up was assessed using knee society scoring system.

Results: Good to excellent results were obtained in almost all the patients using knee society scoring system, mean knee ROM achieved was 114.5 degree. Average time to achieve radiological union was 14.4 weeks. These results were in comparison with the studies done earlier.

Conclusions: Bicolumnar plating is an effective method of treatment of Schatzker type 5 and type 6 fractures and provide excellent result in expert hands. Rehabilitation using early CPM (continuous passive movement) is very effective in reducing the post-operative complications like knee stiffness.
\end{abstract}

Keywords: Tibial plateau fractures, Schatzker, Bicolumnar plating

\section{INTRODUCTION}

Knee injuries are commonly encountered in the ER occurring due to the RTA and fall from height. These high velocity injuries often lead to the intra-articular fractures of proximal tibia. Tibial plateau fractures constitute about $1 \%$ of all fractures and $8 \%$ of fractures in elderly people. ${ }^{1}$ Stiffness, arthritis and instability are major complication of intra-articular fracture of tibia. Soft tissue injury is usually a result of high velocity trauma due to axial loading combined with valgus/varus forces in complex tibial plateau injuries. ${ }^{2}$ Tibial plateau fractures can range from a simple lateral split pattern to very complex bicondylar injuries that can be a source of great disability. Presently, majority of tibial plateau fractures are secondary to high speed motor vehicle accidents and fall from height. ${ }^{3}$ Most studies have shown that most injuries affect the lateral plateau (55\% to $70 \%$ ), isolated injuries of the medial plateau occur in $10 \%$ to $23 \%$ of cases, whereas involvement of both plateaus is found in $10 \%$ to $30 \%$ of reported series. ${ }^{4}$ The goal of treatment of tibial plateau fractures is to get anatomical reduction of the articular surface along with stable fixation permitting early range of motion. The purpose of this study was to assess the 
functional outcome of dual locked and buttress plate in surgical treatment of proximal tibia Schatzker type 5 and 6 fractures and to compare our results with existing literature.

\section{METHODS}

This study was performed in the Department of Orthopaedics, Government Medical College, Jammu. All the patients satisfying inclusion criteria who underwent bicolumnar plating for proximal tibia intra-articular fractures Schatzker type 5 and type 6 from January 2019 to September 2020 were included in the study. A written and informed consent was taken from all the patients for their inclusion in the study. Operative procedure as well as complications of the surgery and anaesthesia were explained well before hand to all the patients in detail in language well understood by them. The collected data of all the patients included in the study design was analyzed and is presented here.

\section{Study design}

This study was an observational prospective study.

\section{Inclusion criteria}

Age between 20 to 60 years. Schatzker type V, VI proximal tibial fractures. Closed fractures and open fractures up to Gustilo-Anderson type I.

\section{Exclusion criteria}

Age less than 20 or more than 60 years Fracture with ipsilateral neuro-vascular deficit and pathological fracture. Old fractures more than 2-week-old.

A total of 28 patients were included for study out of which 2 were lost to follow up. Remaining 26 patients $(n=26)$ were followed up regularly and their data was analysed in detail.

All patients reporting to ER were hemodynamically stabilized, limb splinted, distal neurovascular status was checked and documented, appropriate analgesia was given and IV antibiotics in case of compound injuries following which appropriate radiographs (AP and lateral) of the involved limb with knee and ankle were taken (Figure 1). Computed tomographic (CT) scan was done in all cases to know the intra-articular extension of fracture line (Figure 2). All baseline blood investigation, electrocardiograph (ECG) and chest X-rays were done. Strict limb elevation with a posterior backslab support was given in all cases. The time to surgery was decided by the soft tissue condition and patient fitness. All patients received injection cefuroxime $1.5 \mathrm{~g}$ IV preoperatively as routine prophylaxis.

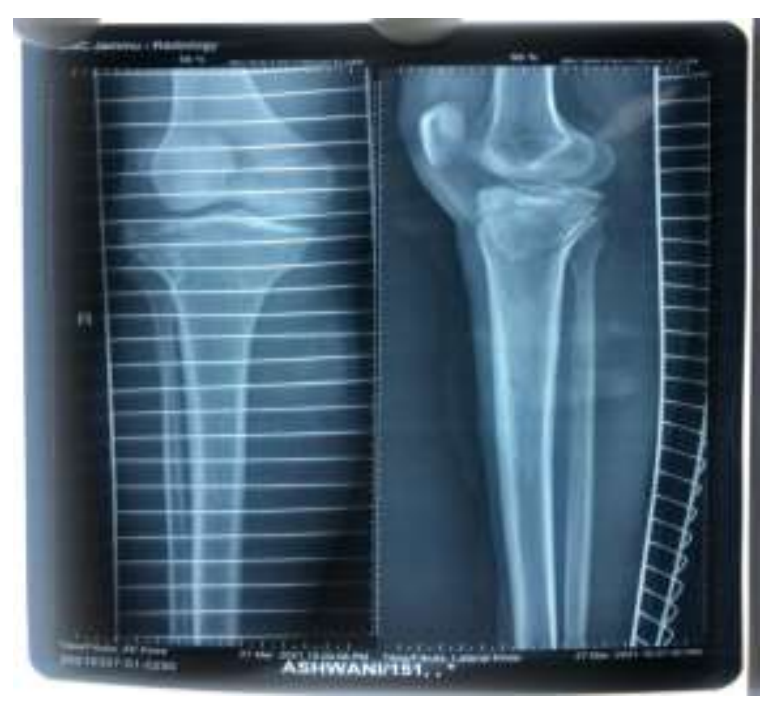

Figure 1: Preoperative X-ray.

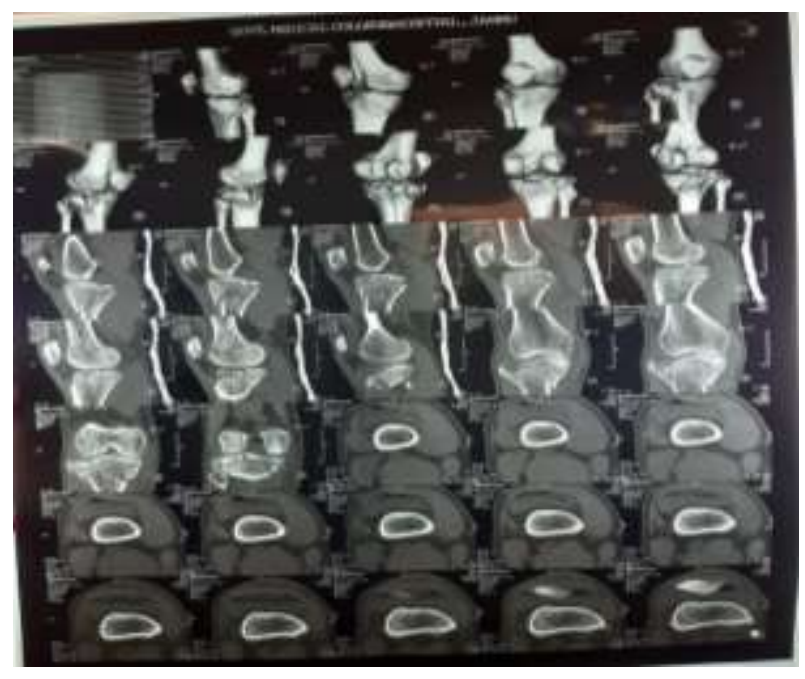

Figure 2: CT scan with 3D reconstruction.

\section{Procedure}

The patient was positioned supine on a radiolucent operating table under spinal or epidural anaesthesia and folded pillow kept under knee to allow knee flexion. Fracture reduction was begun from the medial condyle and first incision was placed approximately $2 \mathrm{~cm}$ posterior to the posteromedial edge of the tibial shaft. The fascia overlying gastrocnemius was incised and the pes anserinus was retracted anteriorly. The intra-articular fracture dislocation was visualized with a sub-meniscal arthrotomy. The impacted fragment was then mobilized (in flexion and external rotation) and reduced. The knee was then extended, and the postero-medial fragment is reduced with the $3.5 \mathrm{~mm}$ proximal tibial T-plate acting as a dorsal buttress and was finally fixed with compression screws in a postero-anterior direction.

The lateral fracture was approached through a lazy Sincision centered over the gerdy tubercle extending about $2 \mathrm{~cm}$ lateral to the tibial crest. The intra-articular damage 
was evaluated through a submeniscal arthrotomy. The fracture was mobilized with a chisel and reduced directly under vision, the articular surface depression was elevated and fracture reduced. A large compression clamp was applied and a lateral buttress plate was used to stabilize the lateral compartment. The skin was closed in layers and posterior above knee backslab was given.

\section{Post op follow up}

Limb elevation was done postoperatively and IV antibiotics were given for 3 days followed by course of oral antibiotics. Weight bearing was restricted till radiological signs of fracture union were seen, however gentle knee ROM was done. Drain removal and X-rays were done on $2^{\text {nd }}$ postoperative day (Figure 3 ). Antiseptic dressing was done on second and fifth postoperative day. Patients were discharged on non-weight bearing crutch walking when they were comfortable and wound was settled. Stitch removal was done around 2 weeks postoperatively. Patients were followed up at 2 weeks, 6 weeks, 3 months and 6 months. Healing was judged by both clinical (pain and motion at fracture site) and radiological (bridging callus at fracture site) criteria and function outcome was reviewed using knee society scoring system.

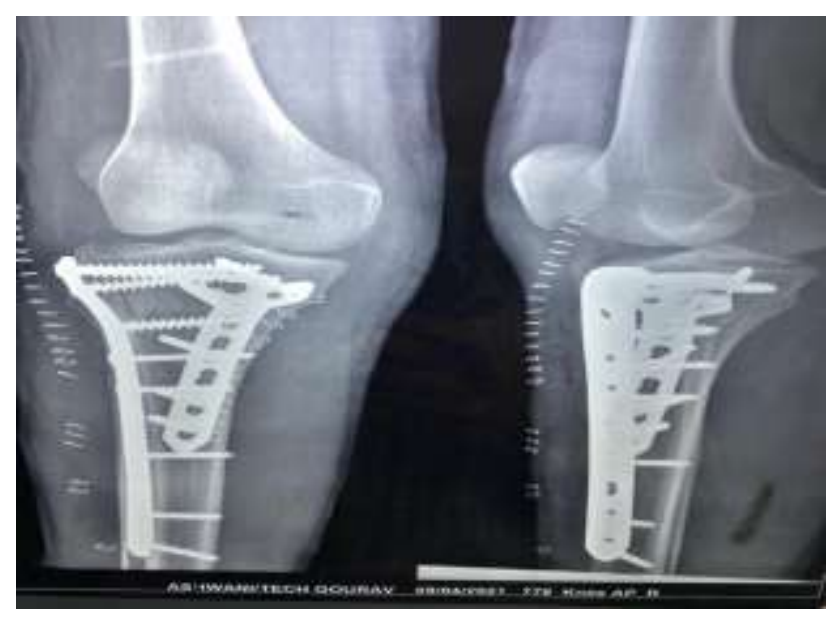

Figure 3: Post-operative X-rays.

Knee society scoring system- (a) 85-100 points: excellent; (b) 70-84 points: good; (c) 60-69 points: fair; (d) $<60$ points: poor.

\section{Radiological assessment}

We took two radiological parameters into account for assessment: (a) medial proximal tibial angle (MPTA): normal $87 \pm 5$ degrees and (b) articular surface step off: normal less than $2 \mathrm{~mm}$.

\section{RESULTS}

In our present study 26 patients $(\mathrm{N}=26)$ were studied, out of which 16 were male $(61.5 \%)$ and 10 were female
(38.4\%). Out of 26 patients, $21(80.76 \%)$ suffered from type 6 Schatzker fracture while $5(19.23 \%)$ suffered from type 5 Schatzker fracture. The most common age group involved was 41-50 years with mean age of 46.5 years (Figure 4).

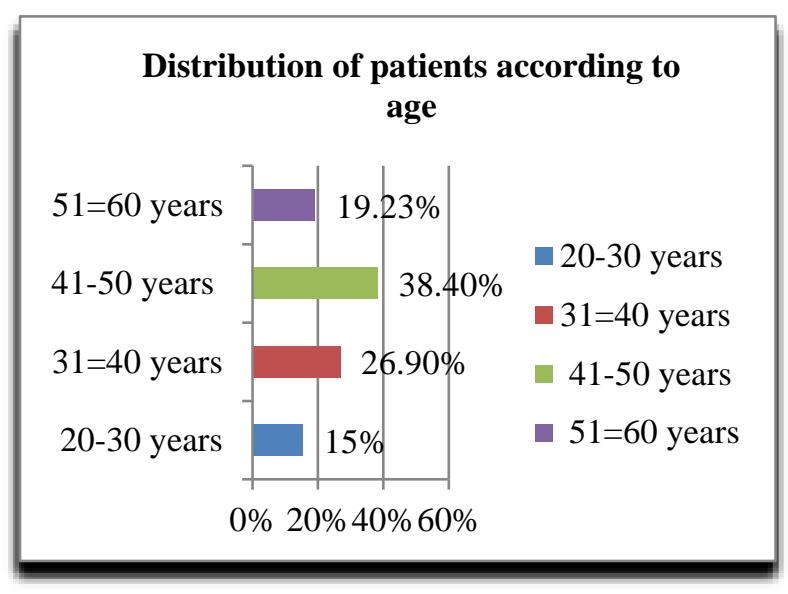

Figure 4: Distribution of patients according to age.

Left limb was involved in 11 patients $(42.3 \%)$ where as 15 patients $(57.6 \%)$ sustained injury to their right limb and no patient was having bilateral injury. In the present study, 22 patients were having closed injury while 4 patients sustained open injury. Majority of patients (24 patients $(92.3 \%)$ sustained injuries due to high energy trauma following RTA whereas 2 patients $(7.6 \%)$ had history of fall from height. All the fractures were classified using Schatzker classification. The surgery was done once the soft tissue swelling subsided and wrinkling sign was present. 7 patients were operated with in 1 week and 19 were operated after 1 week. Mean duration between injury and surgery was 8.2 days. Partial weight bearing was started once the radiological signs of healing started to appear. Almost all patients were walking without aid 6 months post operatively.

Average duration for radiological union was 14.4 weeks (range 12-18 weeks). Mean ROM of knee joint obtained was 114.5 degree (range 100-125 degree). MPTA measurement was undertaken to assess varus/valgus malunion postoperatively. The normal value of MPTA is $87 \pm 5$ degrees. In our series, the average value was 86.4 degrees (range 83-88 degrees). Thus, we found that the normal proximal tibial joint orientation is maintained after bicolumnar fixation in our study. Articular step off was assessed with less than or equal to $2 \mathrm{~mm}$ step off kept as acceptable limit. In our series, 5 cases had articular step off more than $2 \mathrm{~mm}$ (range $3-5 \mathrm{~mm}$ ) and 21 cases had the acceptable result of less than or equal to $2 \mathrm{~mm}$ step off. Statistical calculations and data analysis was done using SPSS software. Functional outcome was evaluated by knee society scoring system and 17 patients $(65.3 \%)$ reported excellent results, 6 patients $(23 \%)$ gave good result while remaining $3(11.5 \%)$ had fair results. Various parameters have been tabulated in Table 1 . 
Table 1: Various parameters studied.

\begin{tabular}{|c|c|c|c|c|c|c|}
\hline \multirow{2}{*}{$\begin{array}{l}\text { Parameters } \\
\text { Parameters studied }\end{array}$} & \multicolumn{2}{|c|}{$\begin{array}{l}\text { Schatzker type } 5 \text { fracture } \\
(n=5)\end{array}$} & \multicolumn{2}{|c|}{$\begin{array}{l}\text { Schatzker type } 6 \text { fracture } \\
(\mathrm{n}=21)\end{array}$} & \multicolumn{2}{|l|}{$\begin{array}{l}\text { Total } \\
(n=26)\end{array}$} \\
\hline & $\begin{array}{l}\text { No. of } \\
\text { patients }\end{array}$ & Percentage & $\begin{array}{l}\text { No. of } \\
\text { patients }\end{array}$ & Percentage & $\begin{array}{l}\text { No. of } \\
\text { patients }\end{array}$ & Percentage \\
\hline \multicolumn{7}{|l|}{ Gender } \\
\hline Male & 03 & 60 & 13 & 61.90 & 16 & 61.5 \\
\hline Female & 02 & 40 & 08 & 38.09 & 10 & 38.4 \\
\hline \multicolumn{7}{|l|}{ Mode of trauma } \\
\hline RTA & 05 & 100 & 19 & 90.47 & 24 & 92.3 \\
\hline Fall from height & 00 & 0 & 02 & 9.52 & 02 & 7.6 \\
\hline \multicolumn{7}{|l|}{ Side of injury } \\
\hline Left & 02 & 40 & 09 & 42.85 & 11 & 42.3 \\
\hline Right & 03 & 60 & 12 & 57.14 & 15 & 57.6 \\
\hline Both & 00 & 0 & 00 & 0 & 00 & 0 \\
\hline \multicolumn{7}{|l|}{ Type of injury } \\
\hline Closed & 04 & 80 & 18 & 85.71 & 22 & 84.61 \\
\hline Open & 01 & 20 & 03 & 14.28 & 04 & 15.38 \\
\hline \multicolumn{7}{|l|}{ Delay in surgery } \\
\hline$<1$ week & 02 & 40 & 05 & 23.80 & 07 & 26.92 \\
\hline$>1$ week & 03 & 60 & 16 & 76.19 & 19 & 73.07 \\
\hline \multicolumn{7}{|l|}{ Articular step off } \\
\hline$<2 \mathrm{~mm}$ & 04 & 80 & 17 & 80.95 & 21 & 80.76 \\
\hline$>2 \mathrm{~mm}$ & 01 & 20 & 04 & 19.04 & 05 & 19.23 \\
\hline \multicolumn{7}{|c|}{ Functional outcome (knee society scoring) } \\
\hline Excellent & 03 & 60 & 14 & 66.66 & 17 & 65.3 \\
\hline Good & 02 & 40 & 04 & 19.04 & 06 & 23 \\
\hline Fair & 00 & 0 & 03 & 14.28 & 03 & 11.5 \\
\hline Poor & 00 & 0 & 00 & 0 & 00 & 0 \\
\hline MPTA & \multicolumn{2}{|c|}{86.2 degree } & \multicolumn{2}{|c|}{86.5 degree } & \multicolumn{2}{|c|}{86.4 degree } \\
\hline $\begin{array}{l}\text { Average duration } \\
\text { for radiological } \\
\text { union }\end{array}$ & \multicolumn{2}{|c|}{14.5 weeks } & \multicolumn{2}{|c|}{14.4 weeks } & \multicolumn{2}{|c|}{14.4 weeks } \\
\hline
\end{tabular}

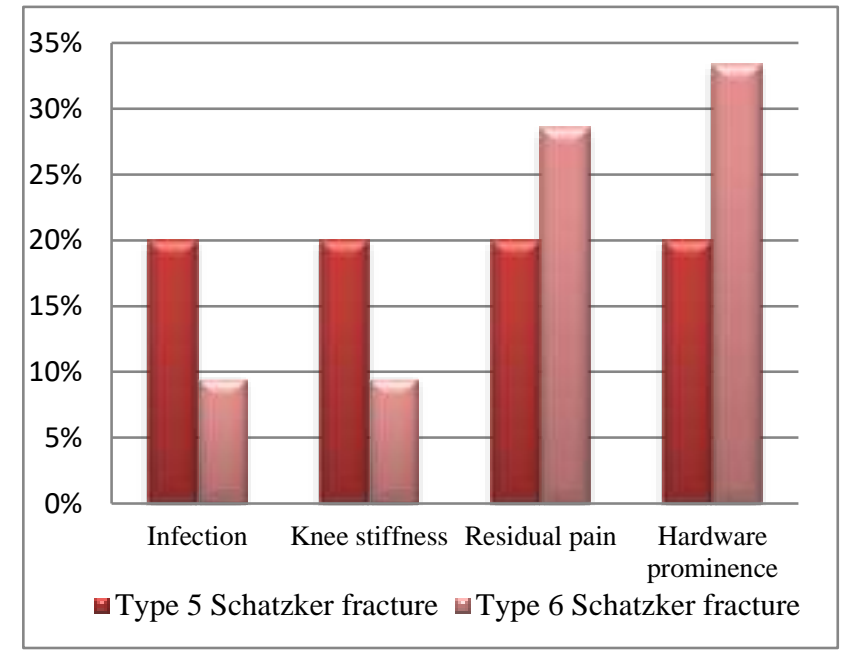

Figure 5: Complications encountered with bicolumnar plating.

In total 3 patient (two diabetics) in the present study suffered from infection which was managed with appropriate culture specific antibiotics and one patient required multiple wound debridements and implant removal later. Three patients complaint of knee stiffness with flexion $<90$ degree. Stiffness was mainly due to poor adherence to physiotherapy that resolved in all by doing aggressive physiotherapy. Rest of the patients didn't complaint of any significant complications. However, pain was complained by 7 patients while 8 of them had hardware prominence. Residual pain did not affect the daily activities of patients which is apparent from good knee society scores of the patients (Figure 5).

\section{DISCUSSION}

Proximal tibia fractures are challenge in itself as these fractures are associated with excessive swelling and soft tissue compromise. Surgery is frequently delayed in most cases to allow for the healing of soft tissue before proceeding with internal fixation. Limited soft tissue covers around proximal tibia lead to more chances of wound complications post operatively. During the surgery proper anatomical reduction has to be achieved to reduce the chances of OA knee and varus/valgus deformities in later stages. 
In our study which included 26 patients, 16 patients $(61.5 \%)$ were male with male to female ratio of 3:2. Male dominance can be attributed to more active lifestyle and higher chances of RTA in males, which is also the most common cause of injury (92.3\%) in present study. Zhang et al in his study had $89.9 \%$ cases sustaining injury by RTA and Prasad et al had all cases $(100 \%)$ due to RTA. ${ }^{5,6}$ Male predominance is also supported by studies done by Eggli et al and Ghayem et al. ${ }^{7,8}$ In present study injury to right limb (57.6\%) was more common than the left $(42.3 \%)$ limb. Type 5 Schatzker fracture were less commonly encountered than the type 6 fractures. This is consistent with the rarity of Schatzker type 5 fractures. In this study, mean duration between injury and surgery was 8.2 days. In a study by Fengluo et al, the mean injury- surgery interval was 8.5 days while study by Gosling et al showed average delay before surgery of 7.5 days., ${ }^{9,10}$ The mean duration of hospital stay day post operatively was 8 days in this study. Average duration for radiological union was 14.4 weeks (range 12-18 weeks) in this study. Bhalotia et al reported mean duration of union 15.2 weeks whereas Fengluo et al found mean union time to be 13.1 weeks and Stannard et al had mean union time of 15.6 weeks. ${ }^{9,11,12}$ So time for fracture union was more or less similar to other studies in the literature. Radiological analysis revealed maintenance of normal proximal tibial knee joint orientation in all cases in this series. The normal value of MPTA is $87 \pm 5$ degrees, and the average value in our series was 86.4 degrees with range between 83-88 degrees. This is further proof of the superior stability provided by bicolumnar plating in bicondylar tibial plateau fractures and the prevention of late varus collapse, which is seen to result in isolated lateral plating. This is an improved result in comparison with the series of Eggli et al. ${ }^{7}$ Accurate articular reconstruction (articular step off $\leq 2 \mathrm{~mm}$ ) was achieved in 21 of 26 patients in our series; which corresponds to $80.95 \%$ accurate reduction. This is comparable to the result published by Eggli et al; they reported $85 \%$ accurate articular reconstruction in their series of 14 patients. ${ }^{7}$ In our study we achieved mean ROM of 114.5 degree. In study by Neogi et al, Faizal et al and Yao et al average range of motion was 124 degree, 110.5 degree and 121.2 degree respectively. ${ }^{13-15}$ We had 3 cases of infection $(11.5 \%)$ in the present study as compared to $17 \%$ infection in study by Steven N Shah whereas Lee et al reported $15 \%$ rate of infection in his study. ${ }^{16,17}$ The incidence of varus malalignment was $0 \%$ in our study. Same results were also seen by Neogi et al and Faizal et al in their studies. ${ }^{13,14}$ However Barei et al out of 31 patients studied had two patients with varus malalignment. ${ }^{18}$ Residual pain and hardware prominence although present in few patients were not troublesome. Table 2 shows comparison with previous literature.

However, long term effects and complications can't be determined because of the short duration of follow up and small sample size which remains a limitation of this study.

Table 2: Comparison with previous literature.

\begin{tabular}{|c|c|c|c|c|c|}
\hline Study & Infection & $\begin{array}{l}\text { Varus } \\
\text { malalignment }\end{array}$ & $\begin{array}{l}\text { Mean knee } \\
\text { ROM }\end{array}$ & $\begin{array}{l}\text { Mean surgery } \\
\text { interval }\end{array}$ & $\begin{array}{l}\text { Average duration for } \\
\text { radiological union (in weeks) }\end{array}$ \\
\hline Khani et al & & & & & 15 \\
\hline Cong et al & & & & 8.5 days & 13.1 \\
\hline Gosling et al & & & & 7.5 days & \\
\hline Zhang et al & & & 121.2 degree & & 14.1 \\
\hline Neogi et al & $15.6 \%$ & $0 \%$ & 124 degree & & \\
\hline Faisal et al & $20 \%$ & $0 \%$ & 110 degree & & \\
\hline Yao et al & & & 115 degree & & \\
\hline Shah et al & $17 \%$ & & & & \\
\hline Lee et al & $15 \%$ & $0 \%$ & & & \\
\hline Present study & $11.5 \%$ & $0 \%$ & 114.5 degree & 8.2 days & 14.4 \\
\hline
\end{tabular}

\section{CONCLUSION}

The operative treatment of fractures of the tibial plateau is challenging. Soft tissue assessment before heading with internal fixation is the ultimate decision that guides the outcomes of surgery. In our present study patients treated by bicolumnar plating have good ROM and radiological healing. Achieving good articular reduction restores the maximal joint stability and congruity, which are very essential for articular cartilage regeneration. The radiological outcome was good which correlates with accurate articular reduction and stability of fracture fixation achieved by bicolumnar plating. Thus, we can conclude that in experienced hands bicolumnar plating gives very good results. Knee stiffness and infection are commonly encountered acute complications which could be avoided by starting early physiotherapy of the joint while infections could be minimised by careful handling of soft tissue envelope. However, long term effects and complications can't be determined because of the short duration of follow up which remains a drawback of this study.

\section{Funding: No funding sources Conflict of interest: None declared}

Ethical approval: The study was approved by the institutional ethics committee 


\section{REFERENCES}

1. Coster TA, Nepola JV, el-Khoury GY. Cast brace treatment of proximal tibia fractures. A ten-year follow-up study. Clin Orthop Relat Res. 1988;(231):196-204.

2. Schatzker J, Mc BR, Bruce D. The tibial plateau fracture. The Toronto experience 1968-1975. Clin Orthop Relat Res. 1979;138:94-104.

3. Schulak DJ, Gunn DR. Fractures of tibial plateaus. A review of the literature. Clin Orthop Relat Res. 1975;(109):166-77.

4. Rockwood CA, David P, Green D, Robert W. Fractures of the proximal tibia and fibula. In: Bucholz RW, Heckman JD, Charles M, Court B, eds. Rockwood and Green's fractures in adults. 6th ed. United States, Philadelphia: Lippincott Williams \& Wilkins; 2006: 1725-61.

5. Zhang Y, Fan DG, Ma BA, Sun SG. Treatment of complicated tibial plateau fractures with dual plating via a 2-incision technique. Orthopedics. 2012;35(3):359-64.

6. Prasad GT, Kumar TS, Kumar RK, Murthy GK, Sundaram N. Functional outcome of Schatzker type $\mathrm{V}$ and VI tibial plateau fractures treated with dual plates. Indian J Orthop. 2013;47(2):188-94.

7. Eggli S, Hartel MJ, Kohl S, Haupt U, Exadaktylos AK, Roder C. Unstable bicondylar tibial plateau fractures: a clinical investigation. J Orthop Trauma. 2008;22(10):673-9.

8. Hasankhani G, Omidi EK, Hassankhani FG, Golnaz. Treatment of Complex Proximal Tibial Fractures (Types V \& VI of Schautzker Classification) by Double Plate Fixation with Single Anterior Incision. Open Journal of Orthopedics. 2013;3:208-12.

9. Luo CF, Jiang R, Hu CF, Zeng BF. Medial doubleplating for fracture dislocations involving the proximal tibia. Knee. 2006;13(5):389-94.

10. Gosling T, Schandelmaier P, Muller M, Hankemeier S, Wagner M, Krettek C. Single lateral locked screw plating of bicondylar tibial plateau fractures. Clin Orthop Relat Res. 2005;439:207-14.
11. Bhalotia AP, Ingle MV, Koichade MR. Necessity of dual plating in bicondylar tibial plateau fracture dislocations: A prospective case series. J Orthop Traumatol Rehabil 2018;10:29-33.

12. Stannard JP, Wilson TC, Volgas DA, Alonso JE. The less invasive stabilization system in the treatment of complex fractures of the tibial plateau: short-term results. J Orthop Trauma. 2004;18(8):552-8.

13. Neogi DS, Trikha V, Mishra KK, Bandekar SM, Yadav CS. Comparative study of single lateral locked plating versus double plating in type $\mathrm{C}$ bicondylar tibial plateau fractures. Indian J Orthop. 2015;49(2):193-8.

14. Faisal. Treatment of Type V and Type VI Schatzker Tibial Plateau Fractures: Comparision of Functional and Radiological Outcomes of Open Reduction and Internal Fixation Using Lateral Lock Plate and Bicondylar Plating- A Randomized Control Trial. IOSR J of Dental and Med Sci. 2020;19(11):35-8.

15. Yao Y, Lv H, Zan J, Li J, Zhu N, Jing J. Functional outcomes of bicondylar tibial plateau fractures treated with dual buttress plates and risk factors: a case series. Injury. 2014;45(12):1980-4.

16. Shah SN, Karunakar MA. Early wound complications after operative treatment of high energy tibial plateau fractures through two incisions. Bull NYU Hosp Jt Dis. 2007;65(2):115-9.

17. Lee MH, Hsu CJ, Lin KC, Renn JH. Comparison of outcome of unilateral locking plate and dual plating in the treatment of bicondylar tibial plateau fractures. J Orthop Surg Res. 2014;20(9):62.

18. Barei DP, Mara TJ, Taitsman LA, Dunbar RP, Nork SE. Frequency and fracture morphology of the posteromedial fragment in bicondylar tibial plateau fracture patterns. J Orthop Trauma. 2008;22(3):17682.

Cite this article as: Singh $P V$, Singh $G$, Singh $M$, Ghani A, Singh A, Lone ZA. Clinico-radiological and functional outcomes of bicolumnar plating in Schatzker type 5 and type 6 fractures of proximal tibia in Tertiary care hospital in North India: a series of 26 patients Int $\mathbf{J}$ Res Orthop 2021;7:709-14. 